\title{
CURRICULUM FOR RESILIENCY: SUPPORTING A DIVERSE RANGE OF STUDENTS' NEEDS IN GRADE 9 MATHEMATICS
}

\author{
Ann Kajander \\ Lakehead University \\ Kelly Sedor \\ Lakehead University
}

\author{
Matt Valley \\ Lakehead University \\ Taylor Murie \\ Lakehead University
}

\begin{abstract}
This study describes the work of one high school team in designing, developing, supporting, and field-testing a new course to support numeracy and general learning skills for a particularly diverse population of students. The rationale, curriculum design, and pilot implementation of the course are situated in existing curriculum structures and recent research around best practices in mathematics teaching and learning, particularly with respect to vulnerable students. The study sought to explore the role and responsibilities of the course designer and teacher, as well as her perception of the challenges and benefits of a custom-designed course for this group of students. The results suggested that the crucial role of the classroom teacher in supporting students emotionally when implementing the intended curriculum for vulnerable students cannot be underscored enough. For such students, teacher-student relationships appeared to be the most important factor in student success, far eclipsing other factors.
\end{abstract}

KeY WoRds: Diverse learners in mathematics; High school mathematics teaching; Resiliency; Secondary mathematics teaching; Students at risk;

\section{BACKGROUND AND CONTEXT}

The Canadian province of Ontario, the location of the study, has undergone mathematics curriculum revision at several times in the past few decades, as have other regions. In the United States, the National Council of Teachers of Mathematics (NCTM) released a document describing the need for mathematics curricula based on problem-solving and inquiry (NCTM, 2000), which has paralleled curricular revision in Canada. At the secondary level, the reformed Ontario Grade 9 and 10 mathematics curriculum was first released in 1999, with further revisions following a few years later (Ontario Ministry of 
Education, 2005a), and a new Grade 9 curriculum is set for release and implementation in fall 2021. Several revisions of the Grades 1-8 curriculum have taken place as well, with the most recent one being in 2020. This was the first revision in 15 years at this level.

Two types of courses were provided in the 2005 Grade 9 and 10 curricula (Ontario Ministry of Education, 2005a), which was in use at the time of writing of this paper, namely Academic and Applied. A third level of course, called "Locally Developed Mathematics" was described in a separate document, with important differences (Ontario Ministry of Education, 2005b). The idea of the Locally Developed course was to allow teachers some flexibility in course design for incoming students who may have very wideranging needs as well as gaps in their learning (Kajander et al., 2018; Ontario Ministry of Education, 2005b). These courses have tended to fall under the radar in that since they do not follow a highly prescribed curriculum in the same way that the Applied or Academic courses do, they fall outside of the mandated provincial testing. The Locally Developed courses were envisioned for students at least three grade levels behind (Ontario Ministry of Education, 2005b). While Ontario released a new de-streamed Grade 9 mathematics curriculum for the fall of 2021, the Locally Developed course structure will remain as is.

In Northwestern Ontario, the region of the study, unique challenges exist. Many incoming high school students live in outlying regions, including First Nations communities as far as $800 \mathrm{~km}$ away, who therefore must move away from home for their high school education (Murie, 2019; Murie \& Kajander, 2019). In Northwestern Ontario, if students are coming to town from reserves for high school education, they often stay with either members of their extended family, or local, often non-Indigenous families who are paid as boarding parents/homes (Murie, 2019; Murie \& Kajander, 2019). These students need to leave their home communities for high school education typically because their communities do not have high schools or the quality of education is limited (Murie, 2019; Murie \& Kajander, 2019). Many of these students have educational gaps, including in their general learning skills, which extend beyond those typical for students entering high school due to various factors (Murie, 2019; Truth and Reconciliation Commission of Canada, 2015). In Northwestern Ontario, as in some other jurisdictions, these factors may include gaps in education due to lack of qualified teachers on reserve schools, intergenerational trauma from residential schools, less funding per student for federally funded schools, a history of various forms of abuse in families, and so on (Indigenous and Northern Affairs Canada, 2017; Truth and Reconciliation Commission of Canada, 2015). If these students' needs are not met, their attendance and engagement in class can deteriorate rapidly (Murie, 2019). The issue of First Nations students needing to leave their home communities for education is a challenge in Northwestern Ontario that is often not fully acknowledged or discussed (Murie, 2019, Murie \& Kajander, 2019). The situation also creates a unique student profile for schools in this area, as these First Nations students are typically grouped with other students who have an array of general learning skills needs.

This study focuses mainly on the work of one teacher seeking to address varying student needs appropriately. Following several years as a school board mathematics consultant, and thus able to observe students and teachers in a range of schools, the teacher in this study returned to a high school as the Mathematics Department Head. Based on her 


\section{Curriculum for Resiliency \\ Kajander, Valley, Sedor \& Murie}

previous experiences, she felt there was a need for a new mathematics course to support some students' mathematics-related learning skills as well as general learning skills, and she successfully advocated with the school administration for the need for such a new course. The study described here documents the unfolding of the course and its implementation.

\section{Course Development}

With the support of the school administration, the department head worked within an existing course structure and particularized it in a way that could assist students in developing the kinds of skills needed to be successful in mathematics, such as numeracy, communication skills, organization, planning, and so on. An existing course structure, a General Learning Skills [GLS] course (Ontario Ministry of Education, 2006) was used to house the new course in order to provide maximum flexibility and expediency in terms of the course approval process. This existing course curriculum structure was not in fact part of the mathematics curriculum documents at all. Rather, it was drawn from the Guidance Curriculum (Ontario Ministry of Education, 2006). The course code, which was the Ontario Learning Strategies 1: Skills for Success in Secondary School (GLS10) course, was the course name used on the school timetable. The use of an existing Ministry of Education approved course, which was flexible enough in description to allow the introduction of mathematical learning skills to be the focus, was a key idea. Using such an existing course structure allowed the school to quickly adapt a Ministry-approved course to their context and needs. This "General Learning Strategies" course is described as focusing on "learning strategies to help students become better, more independent learners" (Ontario Ministry of Education, 2006, p. 27), as stated in the Grade 9 and 10 Guidance and Career Education curriculum document. Hence, the General Learning Skills (GLS) course became the vehicle through which the school was able to provide a newly envisioned mathematics-focused course to support students lacking in subject-specific learning skills.

According to the 2006 revision of the Ontario Ministry of Education's Guidance and Career Education documents (Ontario Ministry of Education, 2006), students should learn how to develop and apply literacy and numeracy skills, personal management skills, and interpersonal and teamwork skills to improve their learning and achievement in school, the workplace, and the community. The Learning Strategies 1: Skills for Success in Secondary School (GLS10) course is meant to help students build "confidence and motivation to pursue opportunities for success in secondary school and beyond" (Ontario Ministry of Education, 2006, p. 27). The above course description only generally mentions the development of numeracy skills, which is slightly further explained in the overall and specific expectations:

\section{Overall Expectations:}

"By the end of this course, students will:

- identify and use a variety of numeracy skills and strategies to improve their practical application of mathematics in everyday contexts" (Ontario Ministry of Education, 2006, p. 28) 


\section{Specific Expectations:}

"By the end of this course, students will:

- apply their knowledge of mathematical facts and procedures in various subject areas.

- connect and apply mathematical concepts and ideas in a variety of problem-solving situations.

- develop and demonstrate the key mathematical processes throughout their learning.

- describe how mathematics is applied in everyday situations (e.g., making financial transactions, budgeting, constructing, scheduling)."

(Ontario Ministry of Education, 2006, p. 28).

The intent of the General Learning Strategies (GLS) courses is to offer students opportunities to enhance their communication and literacy skills to increase their comfort level within their school environment. However, in our previous research, we found that many vulnerable students lack the capacity to demonstrate or communicate mathematical concepts as necessary to be successful in Grade 9 (Kajander et al., 2018). The above Guidance and Career Expectations, while clearly mentioning the role mathematics plays in the course and everyday life, do not incorporate specific expectations for teachers to use to support their students' mathematical needs. While GLS courses nominally address numeracy, it is unclear to what extent previous iterations of GLS courses have specifically addressed numeracy and related learning skills.

\section{GOALS AND FRAMEWORK}

The goals of the study included documenting the journey of the high school Mathematics Department Head and teacher, as she worked to create a new course experience as well as more flexibility in mathematics course pathways for vulnerable Grade 9 students. Exploring the strategies utilized in this course to support students in their learning of both mathematics-related skills and general learning skills to potentially support future classrooms was also an aim for the study. A particular strategy that the group was interested in was the teacher-student relationship and how a focus on a positive relationship supported students. In addition to the impacts on students, the role and level of required commitment by the classroom teacher, as well as the emotional impact on her, were of interest to inform future iterations of this course. The goal of the study was to document the development and operation of the course in its pilot year, from both the designer and teacher viewpoint.

The teacher was interested in participating in this study to document both the experience and what strategies were used with students in order to help inform future iterations of the course. Through participation in the study, the researchers also desired to improve the experience of the students via their involvement in classroom activities (Moreno \& Rutledge, 2018; Robertson, 2000; Wright, 2021). Ongoing informal discussions among the research team members and the course designer and teacher documented the journey and supported its evolution.

The study was situated in the classroom, hence Jao's $(2013,2018)$ model showing the duality of the teacher's focus on the content and social domains for student engagement provided a useful framework. Jao's $(2013,2018)$ work explores the connection between 
student academic learning and classroom engagement in early secondary school, especially as related to the student-teacher relationship. Jao worked in several Grade 9 applied classrooms documenting teacher interactions with students, and found varying levels of emphasis on what she referred to as the academic and social domains (2013). The model suggests that both the social relationships of the teacher with the students and the academic quality of classroom tasks are important in mathematics classes, especially for less traditionally successful learners. Her work suggests that different combinations of these two factors can result in positive learning environments. We wondered about the appropriate relative balance of these two factors in the new GLS course.

Students entering high school are already experiencing a transition, and those students choosing the "Locally Developed" mathematics course tend to have a further range of challenges, both academically and generally (Kajander et al., 2018). The idea of resilience (Hurlington, 2018) helped us further frame the goals of the classroom experience. According to Hurlington (2018), students who have experienced hardships in previous learning can be supported by feeling safe and experiencing caring relationships in the classroom, and it has also been argued elsewhere that positive relationships are the most important factor in intervention settings (Li \& Julian, 2012). These interpersonal factors may relate to the social domain of teacher behaviour in Jao's (2018) framework. In parallel, Hurlington (2018) argues that students can begin to thrive academically by experiencing high expectations together with opportunities for meaningful participation, which in turn align with the academic domain in Jao's (2018) framework. We were interested in the interplay of these factors for this high-needs population, and what the role of the teacher might be.

\section{RESEARCH DESIGN}

This study took place within one high school mathematics department, and describes the creation of this new mathematics course, as envisioned, organized, and initially taught. The study followed a case study participatory action research (PAR) methodology (Merriam \& Tisdell, 2016). The study was determined to be a case study as it occurred in a bounded system (classroom) with a small number of students and co-participants (Merriam \& Tisdell, 2016). The study could also be defined as PAR as the research was not being done on a participant, but instead, with the participant (Merriam \& Tisdell, 2016; Wright, 2021). PAR researchers look to "conduct [PAR] studies in their own communities to specifically challenge power relations and initiate change in their communities" (Merriam \& Tisdell, 2016, p. 57). The power relations being challenged in this study included teacher-student relationships and how they supported students and the internal power struggles within the school about placing students into different levels, and students with gaps in their education that do not fit the standard levels outlined by the Ontario Government (Ontario Ministry of Education, 2005a; Ontario Ministry of Education, 2005b).

The research team consisted of a mathematics education faculty member, three graduate students, and the school Mathematics Department Head, who was also the teacher of the GLS course. The three graduate student researchers worked alongside the teacher as both observers and teacher-participants, often working one-on-one with students, embedded in the research setting. The researchers interacted and formed relationships with the students, and supported the teacher where needed. The researchers also took field notes 
during classes and interviewed the classroom teacher. All had formal backgrounds in mathematics teaching and reform-based approaches (NCTM, 2000).

The classroom teachers and the other researchers brought different perspectives and values to the PAR study (Moreno \& Rutledge, 2018). The classroom teacher was able to bring her day-to-day experiences and expertise in teaching students at the secondary level, and the researchers were able to bring a more academic, research-based approach. In collaboration, the group formed a strong research team with shared goals. To frame the study in PAR, it is important to define the role of the teacher of the GLS class and how she was a part of the research study. The teacher was interested in collaborating with the research team to inform future iterations of this course, and to inform colleagues in other high schools within the school district of any valuable findings.

Classroom visits took place several times a week for a full semester. Each researcher attended the class at least once a week, for a total of 47 classroom visits, hence there was an extra person in the class more than half the time.

Several meetings of the full research team including the teacher took place at regular stages throughout the semester. Meetings took place monthly and therefore were held before, during, and near the completion of the course. Semi-structured interviews with open-ended questions, such as "tell us about your experiences teaching the GLS course" - like those documented in Kajander et al (2018) - were conducted with the teacher before and after the semester of the study. Interviews were approximately one hour in length and were audio-taped and transcribed by the researchers. Field notes taken during the classroom observations as well as after informal conversations with the teacher after class, added to the data sources, along with student attendance records. Field notes and observations were taken by the researchers and the attendance data was recorded and confirmed with the teacher.

We recognize that the classroom is a "complex system" in which researchers must "consider that the whole is greater than the sum of its parts and so calls for more holistic descriptions of the entire system and close analysis of the interrelationship of its parts" (Throop Robinson, 2018, p. 11). As researchers, we also recognize that we have "biases from the standpoint of a privileged outsider when performing AR [action research] with marginalized communities" (Levitan, 2019, p. 11). However, involving the communities directly in the research process as much as possible can assist in addressing inequities (Wright, 2021). The participatory action research lens of ongoing classroom involvement allowed for the possibility of obtaining a more holistic view, in that all researcher observations and field notes were compared and discussed, both with and alongside the voice of the teacher.

\section{MeTHOD}

This study took place in a medium-sized high school (about 1200 students) in a mid-sized urban setting. The school offered all three Grade 9 mathematics course options available at the time of the study: Academic, Applied, and Locally Developed. However, challenges existed within the Locally Developed mathematics classrooms, as we had found in a previous study (Kajander et al., 2018), in terms of students' general learning skills. The 
idea of this new course was to support students in parallel to their mathematics learning, as will be explained further.

The mathematics department head, who also had a strong background in professional development, sought to address the needs she had observed in other Grade 9 classes in terms of students' mathematical learning skills. With the full support of the school administration, the mathematics department head created the "GLS 101: Numeracy" course at her high school. We refer to this course to follow as 'the GLS course'. Practices that engaged this group of students may be useful for future iterations of this course.

\section{RESULTS}

Results are presented in three parts. Part 1 describes the background motivation for, and details of, the course creation from the viewpoint of the teacher who was responsible for creating and teaching it, primarily drawn from the initial teacher interview data. Next, classroom observations, which were mostly drawn from researcher observations and field notes, are presented, and lastly, the data from the final teacher interview, as supported by attendance information, is presented. A three-part narrative style organizes the results.

\section{Part 1 - Designing GLS 101: Numeracy}

Mrs. A (a pseudonym) was a veteran mathematics teacher with a strong background as the board's previous math lead. She returned to the classroom as a department head in a school with very mixed demographics. On the one hand, the school had strong academic mathematics classes with several experienced teachers. On the other hand, several sections of "Locally Developed" (Ontario Ministry of Education, 2005b) mathematics classes were often staffed by non-permanent teachers and were largely populated by students with exceptional life challenges (Kajander et al., 2018; Murie, 2019). Mrs. A explained to the rest of the research team how difficult it could be for students coming out of Grade 8 to adapt to the needs of their new mathematics classrooms, especially in the cases of students with learning challenges beyond just the subject matter of mathematics. As well, as described above, many students arrive from remote communities with significant gaps in their education (Kajander et al., 2018). Some of the remote communities in question are First Nations reserve communities with no access to high school education. As mentioned, these students face additional challenges such as being far from home, experiencing a larger city for the first time, and in some cases, having experienced intergenerational trauma and distrust in education (Indigenous and Northern Affairs Canada, 2017; Murie, 2019). Mrs. A felt there was a need for better support to help students undergoing this transition to secondary level learning, and conceptualized the new course, a GLS credit aimed at helping students lacking in skills and/or confidence in their literacy and numeracy. While the course was to be largely designed with the needs of students in the Locally Developed mathematics course (Kajander et al., 2018) in mind, Mrs. A wanted it to be available to students in any of the three levels of mathematics courses, even if they wanted to join temporarily.

After conceiving the course concept and structure, the next step was to obtain the approval of the administration. Fortunately, Mrs. A had the trust of her administration who provided their full support. She said there was a "very big push on my administration's part to take the risk and let it happen, who also had to push back some 
of the senior management [and] senior staff to say that 'we're going to take the risk, I think that it's worth it"' (Mrs. A, interview transcript). In fact, the administration was invested enough in the idea that they arranged the school timetable in line with Mrs. A's suggestion. The timetable was arranged such that the Grade 9 Academic math, Grade 9 Applied math, Grade 9 Locally Developed math, and the GLS Numeracy courses all ran concurrently in the same period. Period 2 was chosen as the best bet - not first thing in the morning, not right after lunch, and not at the end of the day. The idea was that students struggling in any level of mathematics could attend the GLS course to practice skills, gain confidence, or otherwise receive the one-on-one teacher attention that would help them become successful in their respective mathematics courses. Thus, a student could be registered in any one of the mathematics courses and attend the GLS course occasionally if needed, or they could formally switch classes, moving from math to GLS, without changing the scheduling of the rest of their timetable. Similarly, students who were thriving in the GLS course could, upon agreement of the teachers involved, switch to one of the mainstream mathematics courses and receive credit for that mathematics course instead of the GLS credit. Thus, students could stay in the GLS course all semester and receive a GLS credit, and then take a mathematics course the following semester, or switch to the mathematics course and receive the mathematics credit instead. Or they could simply come to the GLS course for a while instead of their regular mathematics course but remain registered in the mathematics course and then return to it. Support was thus required from the teachers of these other level courses as they needed to work concurrently with Mrs. A and the researchers, allowing their students to leave the classroom if need be so that they could work in the GLS classroom.

The school took a bold stance by not initially populating the newly developed course. At the beginning of the term, no students were enrolled in the course. Mrs. A did not want students registered for the GLS course without prior consultation, as she did not want students placed in it if they did not truly need to be there. She explained that when a course is open and has slots available, students are often scheduled for it because it fit into their timetable. She felt this way of selecting students for the course would be a disservice to the students that actually needed to be in the class. As such, Mrs. A insisted that she should populate the course herself. Over the first couple of weeks of the semester, Mrs. A spent time visiting other teachers, guidance counsellors, and staff to identify students that she felt would benefit from being enrolled in her GLS class. She regularly commented on the level of risk involved in offering a course that started with no students, while continually showing appreciation to her administration for supporting the initiative.

At the beginning of the semester, Mrs. A visited other classes during period 2, and she identified several students that would benefit from taking part in GLS 101: Numeracy. The needs of these students varied greatly. Some had significant gaps in their education since they were from remote communities and had often missed quite a bit of schooling, while others possessed the mathematical skills necessary but were severely lacking in confidence or general learning skills when it came to the application of those skills. Some students also struggled with literacy or simply the act of being in a classroom. Identified students were invited to switch from their other mathematics courses to the GLS course. Once Mrs. A had some students enrolled, she and the rest of the research team began working with the students to assess their specific needs. This required specific attention 
to each student individually, to initiate a conversation aimed towards setting goals for how they wanted to progress in mathematics and other high school subjects. All this teaching and planning was done while still seeking new students to join the course. Members of the research team played a significant role in the facilitation of the daily course activity, but Mrs. A was truly the designer of it from a conception standpoint.

\section{Part 2: The GLS Mathematics Class Experience}

Due to the nature of the course's construction, the attendance and population in Mrs. A's class tended to fluctuate from one day to the next. It was not uncommon for students to arrive late, miss extended periods of time, or for Mrs. A to get a new student midway through the semester. Sometimes students visited from a neighbouring mathematics class for the day if they were feeling overwhelmed or otherwise had trouble focusing in their respective classroom, regardless of the level. Mrs. A made it explicitly clear to her students as well as other students around the school that her classroom would always be a safe space for them. She would often provide healthy snacks and food for them as many students regularly arrived to her classroom hungry. Students were greeted warmly and welcomed, regardless of who they were, when they arrived, and how long they would be staying. She also made a point to take a genuine interest in the students in her care, always asking each student individually about their hobbies, their family, and their lives outside the classroom. She was intentional and explicit about her relationship-building with each student. Some students would come into class and almost instantaneously put their heads down on the desk and sleep or go on their phones, but Mrs. A seemed to have an endless store of patience and warmth. Even with varying students coming in and out, Mrs. A took an interest in every one of them and was very diligent with assessing their individual needs. "I prepared to be flexible and work in the moment. I had a lot of resources through the applied and other math classes that I could alter to fit the needs of my students that day" (Mrs. A, interview transcript). Mrs. A always had appropriate activities ready for students who were new to the class or just visiting for the day.

The onus of designing and running the course daily fell solely on Mrs. A. She used the curriculum of the existing GLS credit and used her skills and experience as a mathematics teacher to create activities and lessons that addressed the points of the GLS content with a numeracy perspective. She explained:

What I did for the numeracy portion of thinking-if I could use some of those big ideas and activities and weave them into the GLS, then [I thought] that might work. I'm a math teacher so through that math lens, it was easy to do that component. I did a lot of preparing and reading the GLS curriculum to find out what else I needed to do to connect it so that it was a true GLS credit to the community and global issues and citizenship... all of it. (Mrs. A, interview transcript).

On a given day, there were usually five or six students present, depending on attendance and the number of students dropping in from other classes. Of the students formally registered in the GLS Numeracy course, the attendance rates were approximately $65 \%$. While at first glance this might not sound strong, the attendance in the Locally Developed math class rarely exceeded 50\%, and the students in the GLS course were sometimes the 
very ones who had typically not been attending their regular mathematics class (Murie, 2019).

With students coming to this GLS class from so many contexts, it was not always feasible for there to be a full class "lesson" or activity that was appropriate for every single student. Some students were, for example, working at a Grade 6 or 7 level in mathematics whereas others were working towards a Grade 9 math credit with most of their difficulties coming from behaviour or mental health problems. Due to the range in abilities and backgrounds, Mrs. A would often work one-on-one with students or in small groups, discussing a concept or idea before letting them practice on their own. The researchers also provided further one-on-one support for the learners. Mrs. A was constantly circulating throughout the classroom, checking in with students regarding what they were working on, or how they were feeling, and then suggesting the next steps. Many times, Mrs. A would simply sit with them and talk to them about whatever it is that they would want to talk about that day. "I think... I actually did a lot more with the student[s] than I wanted to because I just felt like, 'Did I let [them] not do anything for a number of days?' but it kept [them] coming back. Low pressure, low stress, allowed [them] to stay connected to the school so we did not lose [them]" (Mrs. A, interview transcript). When talking one-on-one with a student, she would often find ways to interweave the math into the conversation. Or she would build an activity for the next day that she thought the students would find interesting, based on her conversations with them. "Because that's why these students are where they're at. They need someone in the instruction phase to push and then pull back and then walk away, and then keep pushing enough and know when to walk away without being offensive" (Mrs. A, interview transcript). For example, many of the students were excited about playing the game Minecraft in class. Instead of redirecting them, Mrs. A designed several different tasks that utilized this application. The small class size was beneficial in this regard as Mrs. A was able to work directly with individual students, pairs of students, or small groups. When a concept or idea was relevant to the entire classroom, such as some of the concepts outside the realm of mathematics, the students would engage in full class discussions with her. Examples of conversation topics that she was able to expand to include mathematical ideas included money, food, work, sports, video games, and television. Her flexibility and creativity were always needed.

A priority for Mrs. A in the GLS course was a strong emphasis on community, and ensuring students felt involved in both the school community and the community at large. She explicitly wanted the class to be a safe place for them but also wanted them to feel secure in their whole school environment. The GLS class often collaborated with other classes in the school on projects to emphasize the importance of this community, such as the times when the GLS class and the Locally Developed math class went to the school's food laboratory to make baked goods to hand out around the school. This activity was another example of Mrs. A's understanding and using the class's interests and strengths to design and facilitate a task that solicited increased student engagement. Despite the combined class consisting of students from a broad range of backgrounds, the students were supported to engage one another in conversation. Mrs. A commented that even this had taken some explicit preparation. She had us ensure that every student was given support to be able to take a role in the activities to the degree to which they were comfortable. Students registered in the class were also very welcoming to the ones who spent only a 
day or two in the GLS classroom. Mrs. A mentioned that creating such a welcoming atmosphere had taken explicit work on her part.

Nearly every student in the GLS class, whether a regularly attending student or not, struggled greatly with both literacy and numeracy. For example, students working in the Foods Lab were following a recipe that required $1 \frac{1}{2}$ cups of an ingredient. Some groups felt they could not do this measurement as 'there was only a half-cup measure'. The students needed help to explore the idea that two of the $1 / 2$ cup measures equalled one cup. This was an example of how Mrs. A recognized when to bring the group together for a teachable moment.

The range of gaps created a large obstacle for Mrs. A as she had to design activities that addressed these needs without the tasks being inaccessible to any given student. In mathematics, the acts of writing, showing their work, or explaining their thinking were often overwhelming for these students. As a result, Mrs. A mentioned to the rest of the research team, many times, that she had to modify her tasks for each individual student and come up with varied ways to assess a student's understanding. "A lot of the tasks I had initially prepared really weren't for the students that I was dealing with. Some of the resources I was able to use in the culminating activities, but it was-they're all different and they should be. So really, I just prepared as the students needed" (Mrs. A, interview transcript). Her energy, flexibility and patience were constantly tested. For example, one student struggled with their literacy, and as a result, their interest in mathematics was minimal. However, this student was very interested in games, and card games in particular. As a means of evaluating the student's literacy and mathematical thinking, Mrs. A challenged this student to design their own card game. She asked the student to test it, modify it, and create a presentation on how someone else could or would play the game. She demonstrated creativity and flexibility in terms of breaking from traditional assessment strategies, to provide students with the maximum chances of success. Because she wanted what the students learned in her classroom to be relevant to their own lives, she often tied concepts and discussions to their interests or other real-world ideas.

Often, she would discuss the idea of proportions and proportional reasoning using food, such as bags of goldfish crackers, which she would bring to class and later let the students eat. "We were able to do that through our fishy activities where we would count and then we would look at the proportion of the grams in a bag and the number of fish in there, then the larger sizes proportionally if you buy a bigger size" (Mrs. A, interview transcript).

On some days, due to extenuating circumstances in a student's life or due to their mood, students would disengage from an activity. In these situations, Mrs. A would gently try to encourage them to work on something else, or just participate in a discussion. Sometimes the students would get back into the task at hand with these interventions. Other times, however, no matter what anyone said or did, the student did not want to participate. Mrs. A explained she "would let these students have their time and try again next time," often saying "tomorrow is a new day". 
The semester ended with a collaboration between Mrs. A's GLS class and the students in the Locally Developed mathematics course. The students worked cooperatively to create a variety of foods in the school Foods Lab. During this culminating task, "when we did the cooking... [we explored what happens] if you double a recipe, if you half a recipe... and used tangible ideas, things they could relate to" (Mrs. A, interview transcript) to evaluate the students' abilities to read and follow recipes as well as communicate and work effectively with others in the school community. The activity lasted several days and motivated all the students to participate in at least some way, which was not always the case in the regular class. For example, students who were often shy and reserved took on leadership roles and used their previously developed baking knowledge and experience to help their peers regardless of which class they were in.

Every day in Mrs. A's GLS class was different, as it needed to be. With different students in the room every week, the vast range in abilities, students coming from tumultuous or unstable home lives, as well as the task of improving the literacy and numeracy of students who struggled with mathematics, Mrs. A continually adapted to what was in front of her on a given day. Some constants remained however. Her patience, energy, determination, and care for the students did not waver. Mrs. A provided a safe space for students to come to regardless of their understanding of mathematics, their attitude, or what they were able to do in class on that day.

\section{Part 3: Teacher Reflections}

Mrs. A spoke a great deal about the drastic life circumstances many students were dealing with outside of the classroom. She explained that at home, the kids would experience a great deal of "alcoholism, abuse, death, suicides... taking care of [their younger] siblings, no food, drug abuse themselves, smoking holy [paused and shook her head]... smoking lots. I do not mean just drugs but just smoking itself. Sometimes they even were having to fend for themselves at home or simply be living on their own" (Mrs. A, interview transcript). Establishing her classroom as a "safe space" that was welcoming and supportive to her students was a constant goal. Mrs. A also recognized the impact her relationships with her students had on their behaviour and engagement in the course. It was clear from her demeanour, habits, and the routines she used within the classroom, that she wanted all students who entered her room to feel safe, welcomed, and that they belonged. She was explicit that this was an important goal for her.

Just being in a room where someone can talk to you, maybe give you a snack, maybe just have a chance [for the students] to say [to themselves], '...I'm going to be safe for an hour' ...And then you know, I would say maybe one question [at a time]. Just do a warmup [that day] and [maybe] that is good... Those are the challenges and outside of their own personal fears and inability and lack of understanding, low... low educational supports - that is not right. But they do not have any supports to move their education forward as soon as they leave the classroom. There is no one in their life, a lot of times, that can help drive that need to learn. Then the opposite is true where they just suffer from anxiety because they do want to do well but they have never been able to see success. (Mrs. A, interview transcript) 
When Mrs. A was asked if this course could be generalizable in any form that would make it accessible to other schools, she explained that if she had to create some sort of pamphlet to share with other schools, the first section or chapter would emphasize the importance of teacher-student relationships. In her opinion, every class should be approached in this way, but it is especially crucial for groups of vulnerable students such as those found in this class. Mrs. A stressed again that this type of class needs to be a warm environment where students know they can come to, and some days, not do anything other than be in a safe place if that is in the best interest of the student on that day.

Another important component of Mrs. A demonstrating her caring was her intentional focus on nutrition. It appeared that an integral component to having any kind of consistent attendance in this class, coupled with a safe environment, was the presence of snacks, which Mrs. A knew, and thus provided regularly throughout the semester. She felt students needed to feel safe while also knowing that they could freely have an apple or some other kind of food. Many students did not eat before coming to Mrs. A's class, so this was the first thing they ingested in their day. In addition to helping nourish the students, she described how this helped to foster a caring environment where students were willing to start opening themselves up and be engaged in their learning of mathematics, as well as feeling comfortable trying things while knowing they might make mistakes.

In the final interview, Mrs. A stressed that teachers should want to talk to students about numbers and math in a more informal manner. She explained that many of the students in the GLS course, while at grade level age, had not taken a traditional math course since their junior years of elementary school and were performing significantly below grade level. Thus, exposing them to content-heavy mathematics immediately upon entering Grade 9 was nowhere near beneficial regarding their self-efficacy towards math. She felt that only after mathematics was discussed informally and numbers became not so overwhelming to students should educators slowly start to introduce numbers and mathematical content in a way that does not create fear. Mrs. A explained that one way to do this would be having students look up interesting statistics online about the environment or an area of their interest and use that as a starting point. She noted that if other schools and educators are thinking about running a similar course to GLS 101: Numeracy, they should first get to know their students and student's needs. In Mrs. A's opinion, this caring relationship aspect, which she argued is crucial to effective facilitation, was the only generalizable aspect of this course.

\section{Discussion}

The data provided a rich set of examples of all the elements explicitly needed to raise students' resilience, as described by Hurlington (2018). For example, Mrs. A demonstrated high expectations for the success of students enrolled in the GLS course, by advocating for it in the first place, as well as the personal attention she gave each student, never giving up on them. Through her energy, dedication, passion, and plain hard work, Mrs. A envisioned the design of the course, arranged for it to be appropriately timetabled, personally populated it, and facilitated it. Every day, she provided opportunities for meaningful participation (Hurlington, 2018), by providing individualized learning opportunities for her students, while conveying her high expectations of them. Most importantly, Mrs. A created caring and nurturing relationships (Hurlington, 2018; Li \& Julian, 2012) with her students in many ways, 
including finding out about them as people, welcoming them no matter what, providing food for them, and so on. Jao (2013) affirms the positive effects that strong teacherstudent relationships have on students' behaviour and engagement. In describing a teacher in her study, Jao (2013) explains, "in addition to garnering respect from her students, [the teacher's] relationship with her students makes them feel safe and comfortable. The respect that [the teacher] earns from her students is not out of fear, but rather out of caring" (p. 154). Jao (2013) adds, "the students know that [the teacher] cares about them as people and thus, the students feel like they are a part of a caring community. The students know that with [the teacher] at the helm looking out for their best interests, their community is a safe environment" (p. 154). This position was explicitly prioritized in Mrs. A's classroom. While in Jao's study, different teachers in the grade nine applied mathematics course had differing emphases on the academic and social domains, the latter of which included relationships, Mrs. A's priority was the establishment of a relationship. In our previous work with students in a locally developed course, students told us over and over that, they came to class because they liked the teacher (Kajander et al., 2018), and Mrs. A prioritized such relationships. Hence while the Jao model (2013) is illustrated by intersecting sets showing the academic and social domains, with the relative size of each varying by the teacher, we theorize that the model for Mrs. A's GLS class, which may also apply to other vulnerable groups, would have the academic domain fully contained within the social domain, as illustrated in Figure 1.

Figure 1. Revision of Jao's (2013) model for highly vulnerable students

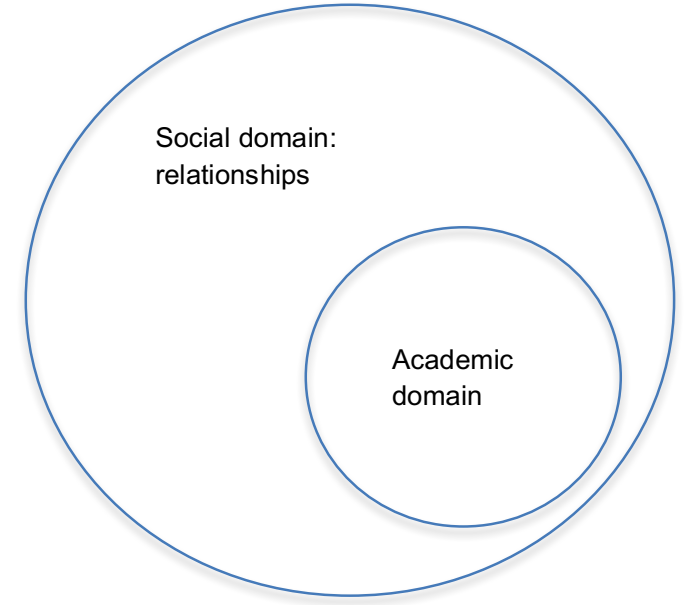

Mrs. A faced unusual challenges with the students in the GLS course and her dedication and explicit use of resilience principles appeared to be crucial factors in the course delivery. She faced many student behaviour challenges daily, and hence, we theorize that teacher resilience may also play a role, in that "the resilience of teacher leaders is a key factor in school reform" (Patterson et al., 2004, p. 3). Additionally, this capacity for teacher resilience is "a crucial element in classroom success" (Bobek, 2002, p. 202). Resilience in this case can be described as "using energy productively to achieve school goals in the face of adverse conditions" (Patterson et al., 2004, p. 3). Thus, it may be through their capacity for resilience that an educator can foster care and learning in students with poor outlooks on mathematics, or otherwise troubling life circumstances. In turn, as Jao (2013) argues, when students feel cared for and safe, they are more receptive to engaging in mathematical content. This approach was apparent in Mrs. A's class, as even when students were in foul moods or had unthinkable things going on in 
their personal lives, they attended whenever they were able. Furthermore, they put effort into their education, which for some, was the first time in years.

The data in the current study elevates the importance of caring relationships in mathematics learning, for vulnerable students as described, to a critical level. Students regularly mentioned informally to the researchers that their relationship with their teacher was what brought them to class, which aligned with our work with students in locally developed classes (Kajander et al,, 2018). Mrs. A herself began the course by establishing individual relationships with every student, specifically catering any work to them individually, and acknowledging their emotional needs on any given day. It may be the case that teachers who wish to facilitate a course like the GLS course described above, may need to let go of any preconceived notions of a normal day-to-day mathematics class schedule, and think much more broadly and holistically of student needs, particularly emotional needs.

\section{CONCLUSION}

Students in the GLS course were hand-picked by the teacher, Mrs. A, as the ones not currently thriving in their regular math class. These students were often selected due to their poor attendance or their lack of engagement in course content and with course materials. So, while "success", using any form of traditional measurement of student achievement may be difficult to quantify here, it is possible to discuss in comparison to what happened with similar groups of students who did not have such a course available (Kajander et al., 2018; Murie, 2019), where attendance was often under $50 \%$ and sometimes as low as 30\%. As well, given that the students in the GLS course were the very ones not thriving in their current math class, and often not attending, the attendance figures of over $50 \%$ ranging at times to $75 \%$, as documented in the GLS course, suggested some improvement in positive engagement by the students rostered, compared to the typical case of similar groups of students in other courses. Additionally, Mrs. A's recognition of their academic growth, again in a more informal sense of the phrase, provides evidence that these students may have been benefiting from positive relationship-based care in a mathematics classroom setting.

The teacher, Mrs. A, while providing opportunities for academic engagement, focused significantly on the relationships developed with the students. She felt that the critical importance of the development of caring relationships with each of these students was "the only take-away". Hence her priorities aligned more with the social domain of Jao's (2018) framework, while strongly demonstrating the importance of supporting these caring relationships in a secure and safe environment, as advocated by Hurlington (2018).

This study demonstrated all the elements of Hurlington's (2018) characterization of using ideas of resilience to support students in secondary school mathematics, namely providing a safe environment, having high expectations, providing opportunities for meaningful participation, and most importantly having an explicit focus on developing caring relationships. The resiliency of the teacher also seems an important consideration (Bobek, 2002). The current data underscores the crucial need for an emphasis on caring relationships, suggesting that the mathematics learning for some students may be developed only within the overarching existence of a strong teacher-student relationship, 
within the resiliency structure. For a teacher trained in the subject-discipline of mathematics, this may be a very new approach indeed.

\section{ACKNOWLEDGEMENTS}

We are deeply indebted to the classroom teacher as well as school administration for allowing us to participate in this study.

\section{REFERENCES}

Bobek, B. (2002). Teacher resilience: A key to career longevity. The Clearing House, 74(2), 202-205. https://www.jstor.org/stable/30189740

Indigenous and Northern Affairs Canada. (2017). Let's talk on-reserve education: Survey report. https://www.sac-isc.gc.ca/eng/1509019844067/1531399883352

Hurlington, K. (2018). Support to thrive: Resilience in students in secondary schools. In A. Kajander, J. Holm \& E. J. Chernoff (Eds.), Teaching and learning secondary school mathematics: Canadian perspectives in an International context (231-244. Springer International Publishing.

Jao, L. (2013). Perceptions, pedagogies, and practices: Teacher perspectives of student engagement in grade 9 applied mathematics classrooms (Doctoral Thesis). University of Toronto, Toronto, Canada. https://tspace.library. utoronto.ca/handle/1807/35856

Jao, L. (2018). Considering both academic and social domains: Increasing student engagement in at-risk classrooms. In A. Kajander, J. Holm \& E. J. Chernoff (Eds.), Teaching and learning secondary school mathematics: Canadian perspectives in an International context (257-268). Springer International Publishing,

Kajander, A., Flessa, J., Lampo, A., \& Sedor, K. (2018). Pitfalls of autonomy: The overlooked challenges of teaching locally developed mathematics in Ontario high schools. Canadian Journal of Science, Mathematics and Technology Education, 18(2), 164-176. https://doi.org/10.1007/s42330-018-0013-4

Levitan, J. (2019). Ethical relationship building in action research: Getting out of Western norms to foster equitable collaboration. Canadian Journal of Action Research, 20(1), 10-29.

Li, J., \& Julian, M. M. (2012). Developmental relationships as the active ingredient: A unifying working hypothesis of "what works" across intervention settings. American Journal of Orthopsychiatry, 82(2), 157-166.

Merriam, S. B., \& Tisdell, E. J. (2016). Qualitative research: A guide to design and implementation (4th ed.). Jossey-Bass. 
Moreno, G. A., \& Rutledge, D. (2018). A response to strategies and tactics through participatory action research in a developmental mathematics course. Educational Action Research, 26(3), 420-438. https://doi.org/10.1080 /09650792.2017.1351384

Murie, T. (2019). Re(righting) mathematics education: Changing students' attitudes towards mathematics through Indigenous knowledge and worldview. [Masters Thesis] Lakehead University, Thunder Bay, Ontario. http://knowledgecommons. lakeheadu.ca:7070/handle/2453/4514

Murie, T., \& Kajander, E. (2019, January 25). Revisioning the three R's: Relationships, resilience and resources [Short oral presentation]. Fields Institute MathEd Forum, Toronto, ON. https://video-archive.fields.utoronto.ca/view/10101

National Council of Teachers of Mathematics. (2000). Principles and standards for school mathematics. NCTM.

Ontario Ministry of Education. (2005a). The Ontario Curriculum: Mathematics, Grades 9 and 10 (revised). Queen's Printer for Ontario.

Ontario Ministry of Education. (2005b). The Ontario Curriculum: Locally Developed Compulsory Credit Courses Grades 9 and 10 Mathematics. Queen's Printer for Ontario.

Ontario Ministry of Education. (2006). The Ontario Curriculum: Guidance and Career Education, Grades 9 and 10 (revised). Queen's Printer for Ontario.

Patterson, J., Collins, L., \& Abbott, G. (2004). A study of teacher resilience in urban schools. Journal of Instructional Psychology, 31(1), 3-11.

Robertson, J. (2000). The three Rs of action research methodology: Reciprocity, reflexivity and reflection-on-reality. Educational action research, 8(2), 307-326.

Throop Robinson, E. (2018). Mapping complexity in an elementary mathematics classroom. Canadian Journal of Action Research, 19(3), 5-33.

Truth and Reconciliation Commission of Canada. (2015). Calls to action. http://trc.ca/assets/pdf/Calls_to_Action_English2.pdf

Wright, P. (2021). Transforming mathematics classroom practice through participatory action research. Journal of Mathematics Teacher Education, 24(2), 155177. https://doi.org/10.1007/s10857-019-09452-1 


\section{BIOGRAPHICAL NOTE:}

Ann Kajander is a professor in the Faculty of Education at Lakehead University. She is interested in supporting teacher development at all levels. Her research interests include exploring and supporting the development of specialized content knowledge for teachers. A recent study examined the development of culturally appropriate mathematics lessons as well as supporting disadvantaged students.

Matt Valley is a high school mathematics teacher who completed his Masters at Lakehead University. He was involved in research in grade 9 locally developed mathematics classes. As well as teaching, he is a busy volunteer, father, and hockey coach.

Kelly Sedor received his bachelor of Education and Master degree from Lakehead University, and studied teacher needs when supporting disadvantaged students in Ontario grade 9 locally developed mathematics classes.

Taylor Murie has taught college and high school level mathematics, as well as doing graduate level research related to culturally appropriate mathematics contexts and lessons. She is currently a student at the Northern Ontario School of Medicine. 